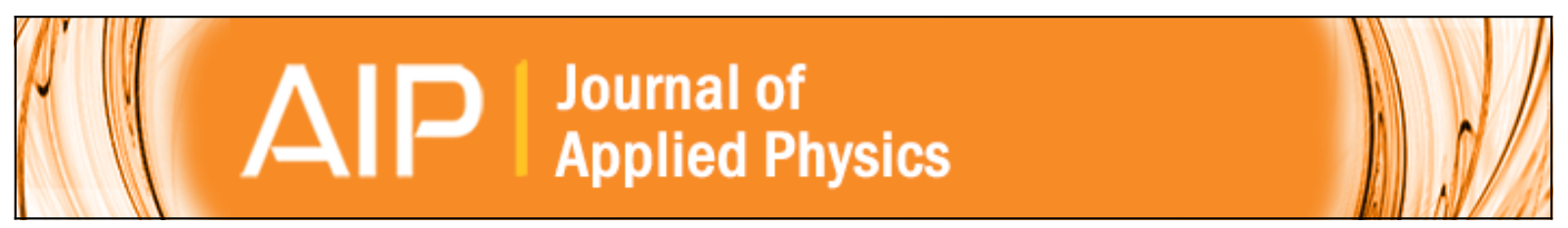

Study of dopant activation in biaxially compressively strained SiGe layers using excimer laser annealing

G. V. Luong, S. Wirths, S. Stefanov, B. Holländer, J. Schubert, J. C. Conde, T. Stoica, U. Breuer, S. Chiussi, M. Goryll, D. Buca, and S. Mantl

Citation: Journal of Applied Physics 113, 204902 (2013); doi: 10.1063/1.4807001

View online: http://dx.doi.org/10.1063/1.4807001

View Table of Contents: http://scitation.aip.org/content/aip/journal/jap/113/20?ver=pdfcov

Published by the AIP Publishing

AlP Re-register for Table of Content Alerts 


\title{
Study of dopant activation in biaxially compressively strained SiGe layers using excimer laser annealing
}

\author{
G. V. Luong, ${ }^{1}$ S. Wirths, ${ }^{1}$ S. Stefanov, ${ }^{2}$ B. Holländer,${ }^{1}$ J. Schubert, ${ }^{1}$ J. C. Conde, ${ }^{2}$ T. Stoica,${ }^{1}$ \\ U. Breuer, ${ }^{3}$ S. Chiussi, ${ }^{2}$ M. Goryll, ${ }^{4}$ D. Buca,${ }^{1}$ and S. Mantl ${ }^{1}$ \\ ${ }^{1}$ Peter Grünberg Institute 9 (PGI-9-IT) and JARA - Fundamentals of Future Information Technology, \\ Forschungszentrum Juelich, 52425 Juelich, Germany \\ ${ }^{2}$ Dpto. Física Aplicada, E.I.Industrial, Univ. de Vigo, Campus Universitario Lagoas Marcosende, 36310 Vigo, \\ Spain \\ ${ }^{3}$ Central Division of Analytical Chemistry (ZCH), Forschungszentrum Juelich, Germany \\ ${ }^{4}$ School of Electrical, Computer and Energy Engineering, Arizona State University, Tempe, \\ Arizona 85287-5706, USA
}

(Received 4 March 2013; accepted 2 May 2013; published online 22 May 2013)

\begin{abstract}
Excimer Laser Annealing (ELA) with a wavelength of $248 \mathrm{~nm}$ is used to study doping of biaxialy compressively strained $\mathrm{Si}_{1-\mathrm{x}} \mathrm{Ge}_{\mathrm{x}} / \mathrm{Si}$ heterostructures. The challenge is to achieve a high activation of As in SiGe, while conserving the elastic strain and suppressing dopant diffusion. Doping of $20 \mathrm{~nm}$ $\mathrm{Si}_{0.64} \mathrm{Ge}_{0.36}$ layers by ion implantation of $1 \times 10^{15} \mathrm{As}^{+} / \mathrm{cm}^{2}$ and subsequent laser annealing using single $20 \mathrm{~ns}$ pulse with an energy density of $0.6 \mathrm{~J} / \mathrm{cm}^{2}$ leads to an As activation of about $20 \%$ and a sheet resistance of $650 \Omega / \mathrm{sq}$. At this laser energy density, the entire SiGe layer melts and the subsequent fast recrystallization on a nanosecond time scale allows high As incorporation into the lattice. Moreover, using these annealing parameters, the SiGe layer exhibits epitaxial regrowth with negligible strain relaxation. ELA at energy densities greater than $0.6 \mathrm{~J} / \mathrm{cm}^{2}$ resembles Pulsed Lased Induced Epitaxy, leading to an intermixing of the SiGe layer with the Si substrate, thus to thicker single-crystalline strained SiGe layers with sheet resistance down to $62 \Omega /$ sq. Effects of energy densities on composition, crystal quality, activation of As and co-doping with B are discussed and related to the spatial and temporal evolution of the temperature in the irradiated zone, as simulated by Finite Element Methods. (C) 2013 AIP Publishing LLC. [http://dx.doi.org/10.1063/1.4807001]
\end{abstract}

\section{INTRODUCTION}

SiGe alloys with their higher hole mobility and small band-gap compared to $\mathrm{Si}$ are being studied as potential $\mathrm{Si}$ channel replacement materials for future p-MOSFETs. Moreover, SiGe/Si heterostructure band-to-band tunneling field effect transistors (Tunnel-FETs) are among the best candidates for future high performance and low operating/ stand-by power logic devices. The use of a small band-gap SiGe alloy as source and a larger band-gap Si as channel and drain side is attractive due to the increased tunnel probability (high $\mathrm{I}_{\mathrm{on}}$ ) and reduced $\mathrm{I}_{\text {off }}$ compared to conventional $\mathrm{Si}$ homostructure Tunnel-FETs. ${ }^{1}$ A critical parameter for the efficient device functionality is the steepness of the source/ drain junctions and their sufficiently high dopant activation. Up to now, several studies were dedicated to the p-type doping in SiGe layers, ${ }^{2}$ while those on $n$-type doping, especially in strained SiGe are very scarce. ${ }^{3,4}$ Tunnel-FET devices, however, require both $n$ - and $p$-type contacts, thus reliable information about $\mathrm{n}$-doping of $\mathrm{SiGe}$ layers is also needed. ${ }^{5}$ The greatest challenge is to achieve very steep and highly doped regions of strained layers while conserving their elastic strain at the same time, since strain is responsible for carrier mobility enhancement. ${ }^{6,7}$ Strain that, dependent on its sign and value, influence the solubility limit of dopants. ${ }^{8,9}$ The major problem of conventional $n$-type dopant implantation, like As and $\mathrm{Sb}$, is the amorphization of the implanted layer, that occurs already at low implantation doses. In a classical Si gate-first implementation process, high temperature rapid thermal annealing (RTA) is employed, but this is in conflict with the low thermal budget, required to avoid strain relaxation and $\mathrm{Ge}$ interdiffusion in $\mathrm{SiGe}$ heterostructures. Laser annealing has been identified as an alternative low thermal budget technique to restore crystallinity and shown to be promising technique for the formation of highly activated ultra-shallow junctions. ${ }^{10,11}$ The possibility to activate epitaxial films by raising the target material temperature to or above the melting point, during a ns-range time scale, makes Excimer Laser annealing (ELA) and Puled Laser Induced Epitaxy (PLIE) therefore very attractive methods for dopant activation in strained SiGe material.

In this work, we present a study using $\mathrm{KrF}$-Excimer laser annealing for As doping of high compressively strained SiGe layers. The aim is to evaluate the dopant activation under strong non-equilibrium laser annealing process conditions, based on fast heating/cooling cycles that (a) keep the alloy below the melting threshold, thus enabling Solid Phase Epitaxial Recrystalization (ELA-SPER) using relatively low laser fluence, and (b) exceed the melting threshold of the alloy, leading to Liquid Phase Epitaxial Recrystallization (ELA-LPER) through high laser fluence ELA and PLIE processes. This last process can be considered as alloys formation through melting and epitaxial recrystallization and is, in general, used when also a fraction of the substrate is molten, thus changes in alloy composition are observed. The obtained experimental results are compared to the temperature profiles 
caused by the first laser pulse, as simulated by Finite Element Methods (FEM), to allow a more comprehensive evaluation of the laser annealing processes. While the emphasis is on As doping, a short comparison with B doped layers by laser annealing and RTP is presented. The purpose of this comparison is solely to address the B co-doping through PLIE processes at high energy densities, that involve a fraction of the $p^{+}$-type $\operatorname{Si}(100)$ substrate.

\section{EXPERIMENTAL}

The investigated $20 \mathrm{~nm}$ biaxially compressively strained SiGe layers with a Ge concentration of $36 \%$ were pseudomorphically grown on $p^{+}$-type $\mathrm{Si}(100)$ wafers with and without a $50 \mathrm{~nm}$ in-situ $n^{+}$doped Si barrier layer between the $\mathrm{SiGe}$ layer and the wafer. This intermediate layer was used for B doped SiGe study to ensure an electrical isolation of the SiGe layer (then $p^{+}-\mathrm{SiGe}$ ) from the $p^{+}-\mathrm{Si}$ substrate, through the formation of a $p^{+}-n^{+}$junction. Details on the fabrication growth process and the properties of the material are described elsewhere. ${ }^{12}$ Raman spectroscopy indicated a biaxial compressive strain of $\varepsilon=1.4 \%$ in the "as-grown" SiGe layers.

Implantation of $\mathrm{B}^{+}$and $\mathrm{As}^{+}$ions was carried out at energies of 1 and $2 \mathrm{keV}$, respectively, with a dose of $1 \times 10^{15} \mathrm{~cm}^{-2}$. In order to avoid channeling, the ion implantation was carried out at $7^{\circ}$ tilt. Information on the projected ion range and the number of vacancies per depth increment and implanted ion is provided by SRIM 2010 simulation software. ${ }^{13}$ The medium ion projected ranges amount to $10 \mathrm{~nm}$ for $\mathrm{B}^{+}$and $5 \mathrm{~nm}$ for $\mathrm{As}^{+}$ion implantations. The local vacancy concentration (Frenkel pair concentration) exceeding the critical dose for amorphization, taken at $c_{v}=20 \%$ of the total atoms concentration ${ }^{14}$ lead for our case of As implantation, to the formation of an $7 \mathrm{~nm}$ amorphous surface layer. Only very low vacancy densities $(<0.01$ vacancy/ ion $\cdot \AA$ ) are induced at the $\mathrm{SiGe} / \mathrm{Si}$ interface avoiding a major generation of defects that could lead to strain relaxation.

The samples were annealed using a commercial KrFExcimer laser emitting at $248 \mathrm{~nm}$, pulses of $20 \mathrm{~ns}$ duration at a repetition rate of $2 \mathrm{~Hz}$. The annealing was performed under $\mathrm{N}_{2}$ flow to avoid sample oxidation. A plano-convex lens was positioned between the laser system and the sample in order to focus the laser beam. By shifting the lens position, the spot size was changed from $0.6 \mathrm{~cm}^{2}$ to $3.4 \mathrm{~cm}^{2}$, to adjust, in conjunction with a change of the pulse energy, the energy density from 0.1 to $1.4 \mathrm{~J} / \mathrm{cm}^{2}$. In order to expose large areas, necessary for some characterization techniques, a stepping motor was used, moving the sample perpendicular through the laser beam, at a constant velocity of $0.1 \mathrm{~mm} / \mathrm{s}$. For comparison, $600{ }^{\circ} \mathrm{C}$ RTA processed samples were prepared. This temperature was low enough to ensure the elastic strain conservation in the layers. ${ }^{14}$

The electrical characterization of the samples was performed using Van-der-Pauw structures with square geometry, fabricated employing standard optical lithography and reactive ion etching. ${ }^{9}$ Crystalline quality of the SiGe layer was investigated by Rutherford Backscattering Spectrometry/ Channeling $(\mathrm{RBS} / \mathrm{C})$ using a Tandetron accelerator with
1.4 $\mathrm{MeVHe}^{+}$ions. For increasing the depth resolution, a backscattering angle of $110^{\circ}$ was chosen. The RBS technique was also employed to accurately determine stoichiometry and thickness of the SiGe layers.

Secondary Ion Mass Spectroscopy (SIMS) was carried out for all samples to determine changes in dopants and $\mathrm{Ge}$ profiles. The analyses were complemented by cross-section Transmission Electron Microscopy (XTEM), giving insights into the material crystallinity and by Raman spectroscopy for the evaluation of strain.

Numerical analysis of the spatial and temporal temperature profiles in the irradiated areas was performed solving the heat conduction differential equation (HCDE) through FEM, using the commercial software ANSYS ${ }^{\circledR}$ 12.0.

\section{RESULTS}

In order to evaluate the experiments in a systematic manner, the results of As activation are presented in the following sequence: (a) electrical characterization; (b) physical and chemical characterization (SIMS, RBS and XTEM); (c) strain analyses based on Raman spectroscopy; and (d) Numerical simulation of the expected temperature profiles caused by the first laser pulse. These results are finally discussed and compared with those obtained for RTA and B doping by ELA and RTA.

\section{A. Electrical characterization of As doped samples}

The sheet resistance measurements for laser annealed As doped SiGe layers using a van-der-Pauw geometry with square contacts, are presented in Fig. 1, split in two energy density windows for better illustration. Different annealing processes in relation with the laser energy density, as will be discussed in the following, are also indicated here. The sheet resistance strongly decreases with increasing laser annealing energy density. An increase of the laser density from $0.1 \mathrm{~J} / \mathrm{cm}^{2}$ to $0.4 \mathrm{~J} / \mathrm{cm}^{2}$, results in a drop of the sheet resistance from $1.2 \times 10^{4} \Omega / \mathrm{sq}$ to $1.2 \times 10^{3} \Omega / \mathrm{sq}$, followed by a slower decrease rate to about $600 \Omega / \mathrm{sq}$ at $0.6 \mathrm{~J} / \mathrm{cm}^{2}$ and

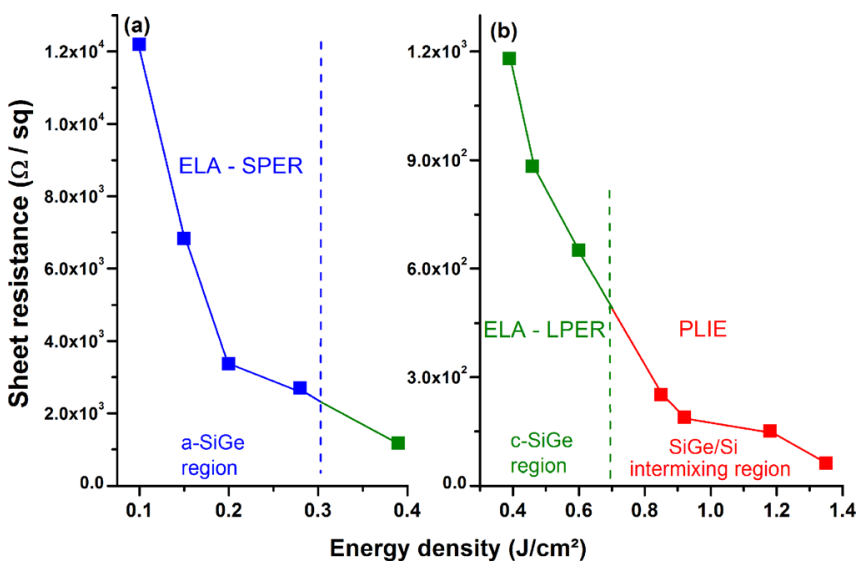

FIG. 1. Electrical characterization of As doped SiGe layers by laser annealing. The sheet resistances vs laser energy density (a) below $0.4 \mathrm{~J} / \mathrm{cm}^{2}$ and (b) above $0.4 \mathrm{~J} / \mathrm{cm}^{2}$, are presented in linear scale. Different annealing processes, as discussed in the following, are indicated. 

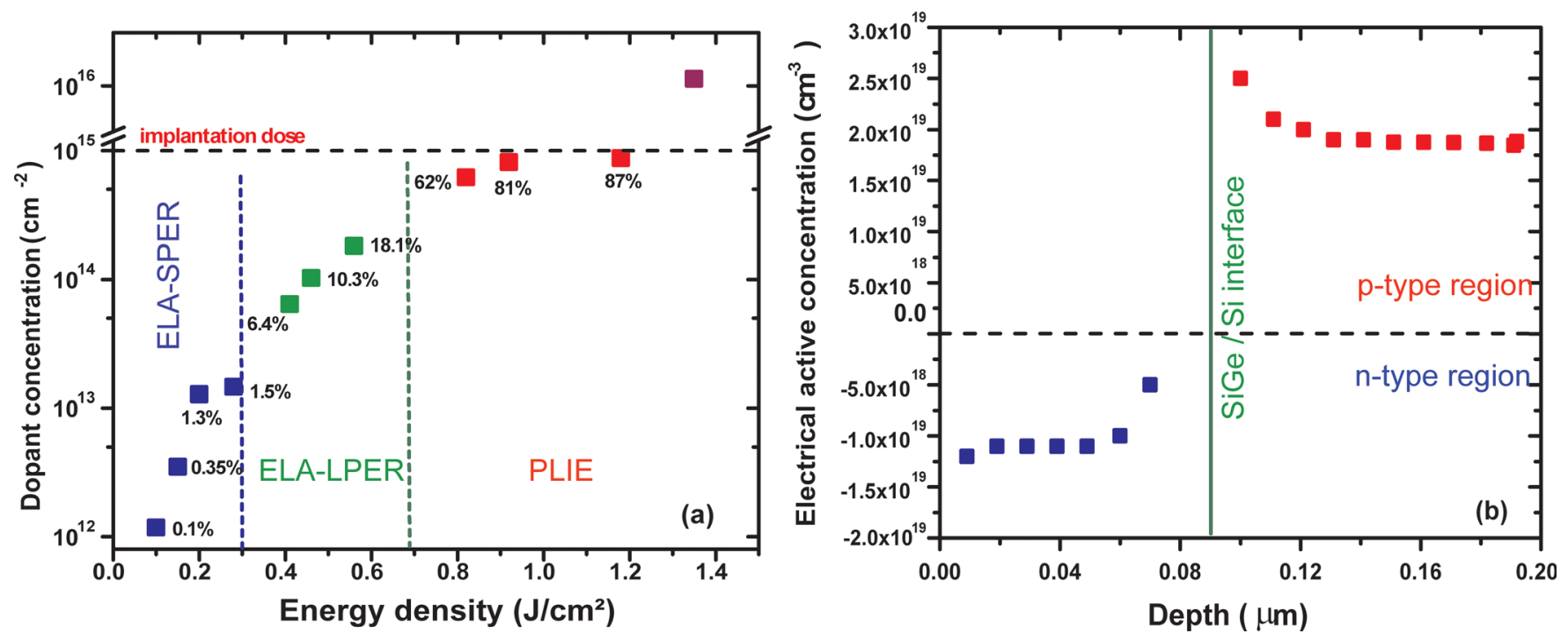

FIG. 2. (a) Sheet dopant concentration vs. laser energy density. The values of dopant activation degree, defined as the ratio of sheet carrier concentration and implanted dose, are given for every energy density. Dashed lines indicate the different energy density regions, previously given in Fig. 1. (b) Carrier concentration profile measured by ECV for a sample treated with $1.18 \mathrm{~J} / \mathrm{cm}^{2}$. A homogenous $1.15 \times 10^{19} \mathrm{~cm}^{-3} \mathrm{n}$-type doping was measured far below the depth of the original SiGe layer. The SiGe layer thickness is now of about $90 \mathrm{~nm}$ and followed by a p-type substrate with doping concentration of about $1 \times 10^{19} \mathrm{~cm}^{-3}$.

reaches $150 \Omega / \mathrm{sq}$ at an energy density at $\sim 1 \mathrm{~J} / \mathrm{cm}^{2}$. The lowest layer resistivity of $62 \Omega / \mathrm{sq}$ is observed for $1.35 \mathrm{~J} / \mathrm{cm}^{2}$.

An important parameter for the evaluation of the efficiency of laser annealing is the electrically active dopant concentration, which has typically a reciprocal behavior with respect to the sheet resistance. The dopant activation, measured employing a Hall set-up as a function of the laser energy density, is presented in Fig. 2(a). Low values of active As of less than $10 \%$ are measured at energy densities below $0.5 \mathrm{~J} / \mathrm{cm}^{2}$, but they rapidly exceed $50 \%$ of the implanted As dose for $0.85 \mathrm{~J} / \mathrm{cm}^{2}$. The active dopant concentration is apparently reaching the As implantation dose at higher laser energy densities. However, at highest energy of $1.35 \mathrm{~J} / \mathrm{cm}^{2}$ a carrier concentration value above the As atoms concentration is measured, which suggest strong substrate contribution through major heterostructure changes. As anticipated in Fig. 1, different energy density regimes seem to strongly influence the behavior of the dopant activation and concentration.

For a more detailed study of the very high activation degree that finally exceeds the theoretical 100\% of the implantation dose, Electrochemical Capacitive-Voltage (ECV) measurements with a reverse-biased semi-conductorelectrolyte contact, have been performed. This technique is used for determining the electrically active doping concentration profiles in semiconductor structures. ${ }^{15}$

Fig. 2(b) presents the electrochemical profile of the SiGe samples processed at a laser energy density of $1.18 \mathrm{~J} / \mathrm{cm}^{2}$. An $n$-type concentration of $1.15 \times 10^{19} \mathrm{~cm}^{-3}$ is determined for an approximately $90 \mathrm{~nm}$ thick SiGe layer, followed by a dominant substrate doping, that was extracted to be $p$-type at $\sim 2 \times 10^{19} \mathrm{~cm}^{-3}$. The ECV profile, therefore, indicates a considerably enlargement of the SiGe layer from initially $20 \mathrm{~nm}$ to about $90 \mathrm{~nm}$ thickness. In order to better understand both, the van der Pauw and ECV data, extensive additional physical and chemical material characterization as well as numerical simulation of thermal profiles produced by the laser radiation has been performed.

\section{B. Morphological evolution under laser irradiation}

A detailed study of the Ge and As depth distributions after laser annealing was performed by SIMS. In Fig. 3, the depth profiles are shown for laser annealing densities below $0.6 \mathrm{~J} / \mathrm{cm}^{2}$. The slopes of the As (Fig. 3(a)) and Ge (Fig. 3(b)) profiles in the low energy density regime up to $0.3 \mathrm{~J} / \mathrm{cm}^{2}$ are comparable with the as-implanted profiles, thus indicating no As diffusion as well as no alteration of SiGe layer thickness and composition. At this laser energy density, the energy absorbed by the SiGe layer is most probably used for recrystallization of the highly implantation damaged/amorphized top layer, to an epitaxial alloy, as can clearly be observed in Fig. 4(a). However, contrast fluctuations in the region near the substrate surface indicate a possible clustering in the fully crystallized As implanted region are visible.

According to the Ge profiles (Fig. 3(a)), at $0.5 \mathrm{~J} / \mathrm{cm}^{2}$ the Ge signal is reduced at the surface of the SiGe layer and
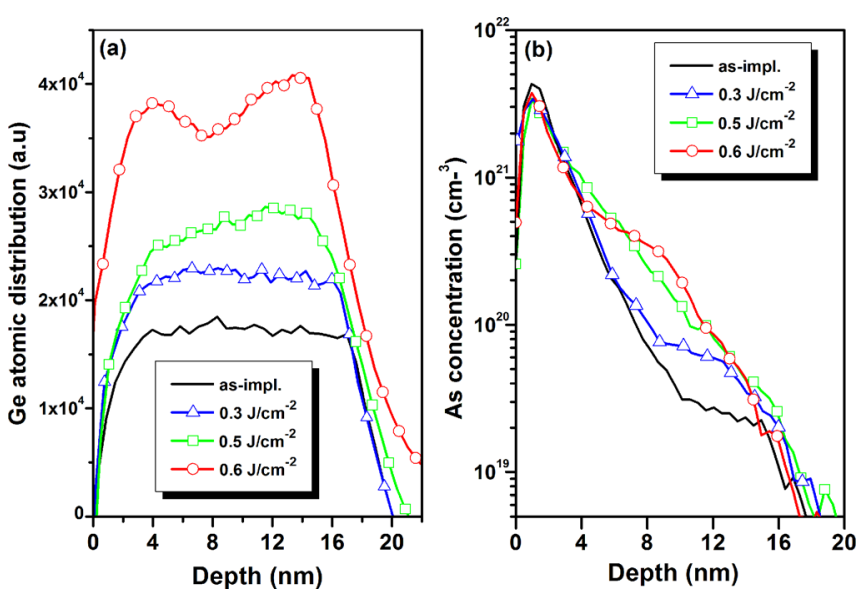

FIG. 3. SIMS profile showing (a) Ge and (b) As-distributions in the SiGe layer after ELA at energy densities below $0.6 \mathrm{~J} / \mathrm{cm}^{2}$. The Ge profiles are plotted in linear scale and arbitrary shifted vertically for a better comparison. 

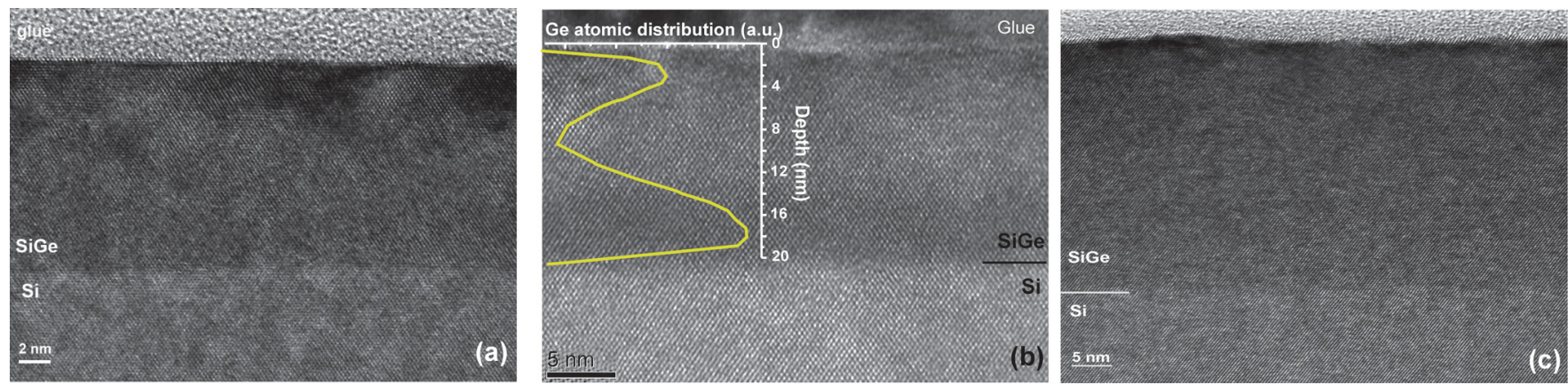

FIG. 4. XTEM images of the SiGe layers after ELA at (a) $0.25 \mathrm{~J} / \mathrm{cm}^{2}$ (b) $0.6 \mathrm{~J} / \mathrm{cm}^{2}$, and (c) $0.85 \mathrm{~J} / \mathrm{cm}^{2}$. For $0.25 \mathrm{~J} / \mathrm{cm}^{2}$ defect formation, e.g., As clustering, in the fully crystallized As implanted region are visible. For $0.6 \mathrm{~J} / \mathrm{cm}^{2}$ the contrast changes with the depth in the SiGe layer in agreement with the SIMS profile; (the inset plot represents the Ge atomic distribution as in Fig. 3(a)). The regrowth yields single crystalline material without no visible dislocations or interface defects.

increases near the $\mathrm{SiGe} / \mathrm{Si}$ interface while at higher laser energy of $0.6 \mathrm{~J} / \mathrm{cm}^{2}$ a minimum in the Ge concentration is observed close to the middle of the SiGe layer. The latter behavior is attributed to the layer melting/recrystallization process, causing element redistribution in the molten alloy. However, the width of the Ge signal and its steepness at the $\mathrm{SiGe} / \mathrm{Si}$ interface are preserved up to a laser density of $0.7 \mathrm{~J} / \mathrm{cm}^{2}$ (plotted in Fig. 5). This is an indication that, up to $0.7 \mathrm{~J} / \mathrm{cm}^{2}$, the melting is restricted to the $\mathrm{SiGe}$ layer. However, the As sims profiles (Fig. 3(b)) show shallower slopes of the depth profile after annealing at $0.5 \mathrm{~J} / \mathrm{cm}^{2}$ and $0.6 \mathrm{~J} / \mathrm{cm}^{2}$ indicating a redistribution of As after short melt/ recrystallization cycles at those energy densities.

These different shapes of the Ge profiles can be related to the heat distribution (melting) in the SiGe layers: First, due to small thermal conductivity of the amorphous layer, steep and high local temperature profile are produced, allowing layer crystallization and later at about $0.3 \mathrm{~J} / \mathrm{cm}^{2}$ melting of the amorphous surface layer. The depth of the SiGe melt increases up to an energy density of around $0.6 \mathrm{~J} / \mathrm{cm}^{2}$ when melting of the complete SiGe layer seems to occur, as indicated by changes in Ge distribution. The change of the profile from a uniform distribution (flat depth distribution) to a non-uniform profile is now clearly observable at $0.6 \mathrm{~J} / \mathrm{cm}^{2}$
(Fig. 3(a)) and, in the XTEM image of Fig. 4(b), where the contrast change along the $\mathrm{SiGe}$ layer thickness indicates higher $\mathrm{Ge}$ content regions near the surface and at the $\mathrm{SiGe} / \mathrm{Si}$ interface. This non-uniform Ge depth distribution may also partially be caused by the temporal evolution of the laser pulses, resulting in a non-uniform motion of the atoms at high temperature during the first order phase transitions in melting/solidification cycles, as observed recently by other groups. ${ }^{16}$ Moreover, the XTEM images demonstrate that the regrowth yields again single crystalline layers.

With increasing energy density, the threshold for melting the $\mathrm{Si}$ is reached, as shown in the SIMS profiles of Fig. 5. While the Si melting point and its thermal conductivity is higher than for SiGe alloys, this Si melting threshold is experimentally found to be around $0.7 \mathrm{~J} / \mathrm{cm}^{2}$, i.e., where the Ge signal starts to exceed the initial $\mathrm{SiGe} / \mathrm{Si}$ interface. ${ }^{17}$ In this case $\mathrm{Ge}, \mathrm{Si}$ and As clearly redistribute in a new diluted and thicker $\mathrm{SiGe}$ layer, as can be seen in the SIMS profiles (Fig. 5) and XTEM image (Fig. 4(c)). The redistribution of Ge in the melted region leads to SiGe alloy thicknesses of $52 \mathrm{~nm}, 90 \mathrm{~nm}$, and $127 \mathrm{~nm}$ at laser densities of $0.92 \mathrm{~J} / \mathrm{cm}^{2}, 1.18 \mathrm{~J} / \mathrm{cm}^{2}$, and $1.35 \mathrm{~J} / \mathrm{cm}^{2}$, respectively (Fig. 5(a)). Accordingly, all As profiles (Fig. 5(b)) follow the Ge distribution profiles (Fig. 5(a)) and stop abruptly at the same depth as the Ge signal.
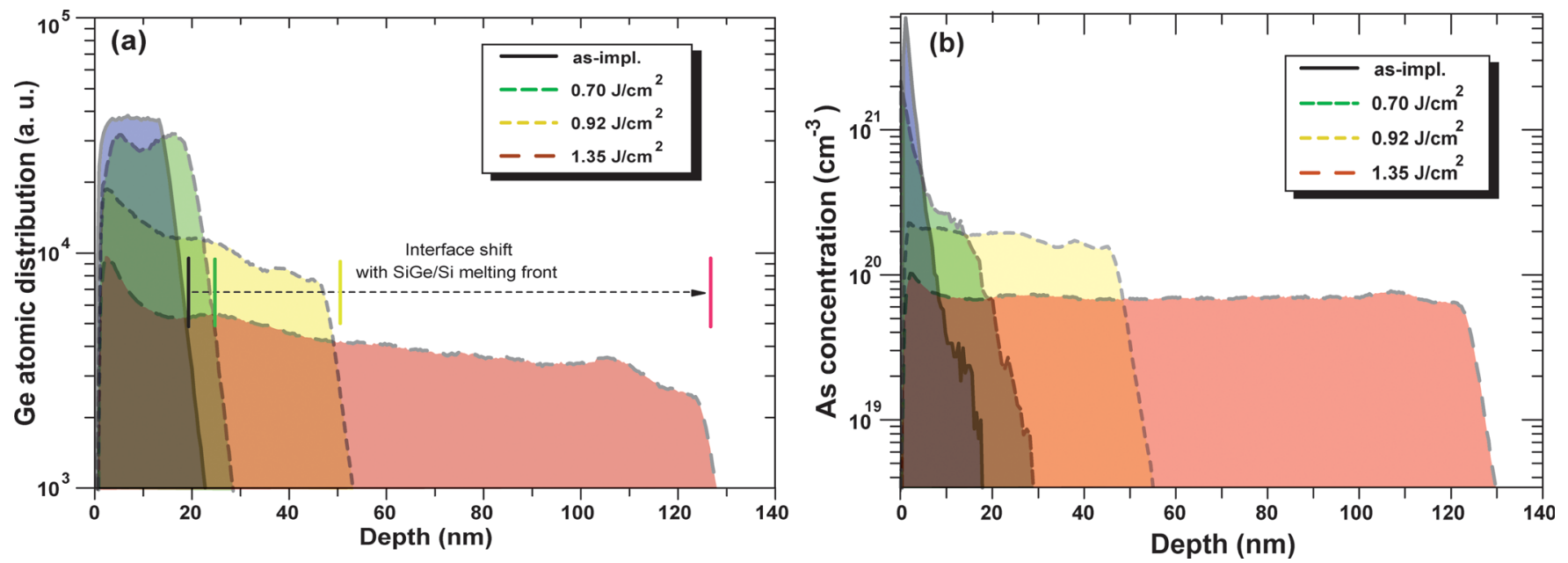

FIG. 5. (a) Ge and (b) As SIMS profile of the SiGe layer after ELA at energy densities of $0.7,0.9$, and $1.35 \mathrm{~J} / \mathrm{cm}^{2}$ which exceed the melting threshold at the $\mathrm{SiGe} / \mathrm{Si}$ interface. 

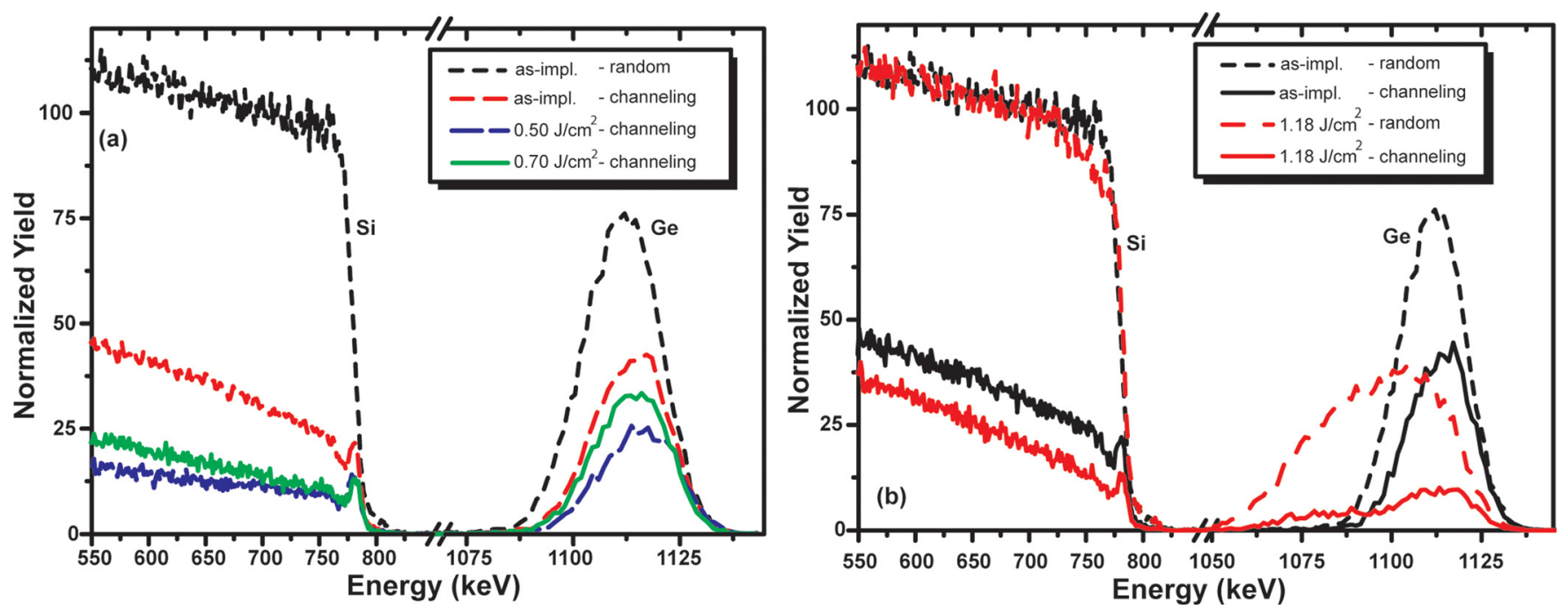

FIG. 6. RBS/C spectra of As implanted SiGe showing the spectra for (a) 0.50 and $0.70 \mathrm{~J} / \mathrm{cm}^{2}$ and (b) $1.18 \mathrm{~J} / \mathrm{cm}^{2}$. Channeling spectra after laser annealing with different energy densities are presented in comparison with the channeling spectrum of an as-implanted sample.

The stoichiometry, the exact layer thickness and the crystal quality of the laser annealed samples have finally been determined using RBS. Figure 6 shows the random and channeling spectra of samples processed with different laser energy densities, in comparison with the as-implanted spectra. The samples annealed at low and moderate energy densities exhibit an improved channeling compared to the as-implanted ones, indicating a healing/recrystallization of the implantation damaged SiGe layer. At $0.7 \mathrm{~J} / \mathrm{cm}^{2}$ a slight dechanneling compared to lower energy densities is observed, but the signal is still lower than in the asimplanted case. The RBS random spectrum, however, does not indicate $\mathrm{SiGe}$ layer melting beyond the initial $\mathrm{SiGe} / \mathrm{Si}$ substrate interface. Further increase of the laser energy density results in a strong increase of the SiGe layer thickness, but also to an improved channeling. Based on these experimental results, we consider that at around $0.7 \mathrm{~J} / \mathrm{cm}^{2}$ the melting point of the $\mathrm{SiGe} / \mathrm{Si}$ interface is reached.

At $1.18 \mathrm{~J} / \mathrm{cm}^{2}$, the random spectrum shows an extensive broadening of the Ge signal, indicting an increased SiGe layer thickness (Fig. 6(b)). RUMP spectra simulation confirms that the initially $20 \mathrm{~nm} \mathrm{Si}_{0.64} \mathrm{Ge}_{0.36}$ layer transforms into a $90 \mathrm{~nm} \mathrm{Si}_{0.92} \mathrm{Ge}_{0.08}$ layer. However, the newly formed
SiGe layer is of high single crystalline quality, as confirmed by a low minimum channeling yield at the interface to the $\mathrm{Si}$ substrate (in the $1060-1100 \mathrm{keV}$ region), indicating pseudomorphic regrowth.

\section{Strain analyses by Raman spectroscopy}

Raman spectroscopy is a well-established nondestructive tool to analyze mechanical stress and composition in semiconductor materials. The large Raman peak at $520.5 \mathrm{~cm}^{-1}$ in Fig. 7 represents the Si-Si vibration modes of unstrained $\mathrm{Si}$, whereas the small peaks correspond to $\mathrm{Si}-\mathrm{Si}$ vibration modes within the different SiGe layers. Based on the position of the vibration modes, the elastic strain in the SiGe layer can be calculated according to equation

$$
\omega_{\mathrm{SiGe}}=520.5-62 \cdot c_{\mathrm{Ge}}-815 \cdot \varepsilon_{\mathrm{SiGe}}
$$

where $\omega_{\mathrm{SiGe}}$ is the position of the $\mathrm{Si}$-Si vibration mode within the SiGe layer, $c_{G e}$ represents the Ge content, and $\varepsilon_{\mathrm{SiGe}}$ the residual strain. ${ }^{18}$ The correct position of the peaks is extracted by signal deconvolution using a double Lorentz function, as indicated in Fig. 7. The Ge content is separately determined

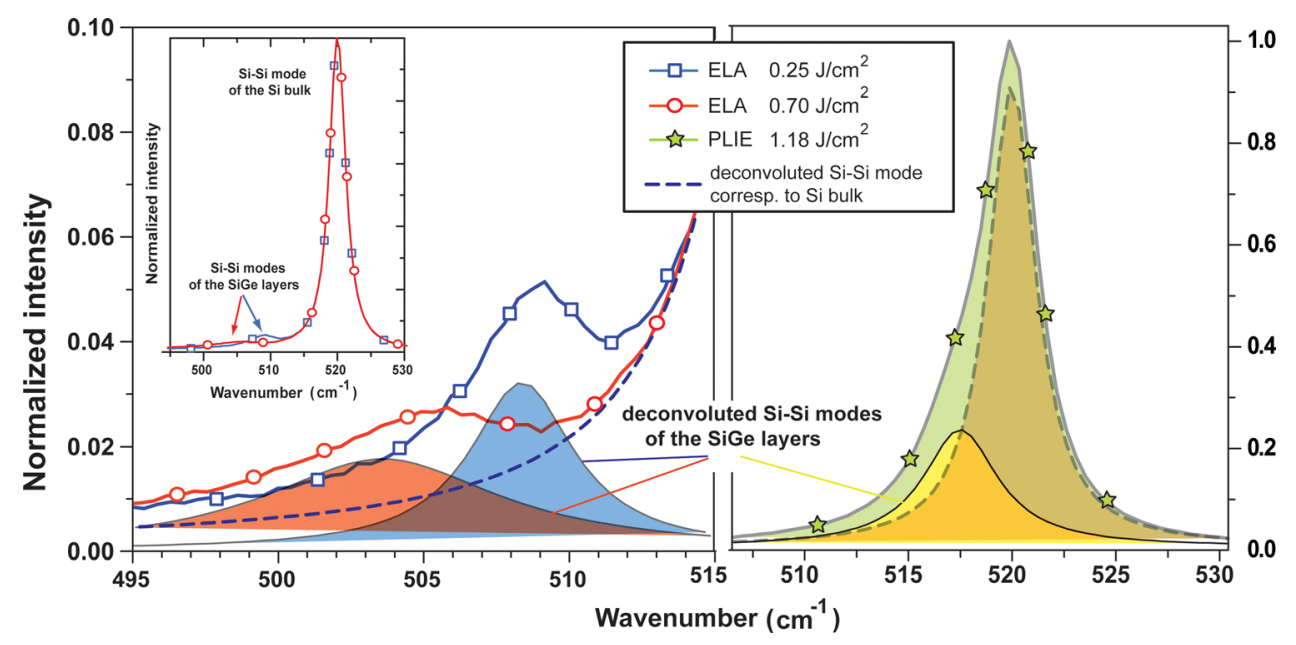

FIG. 7. Raman spectra of As implanted $\mathrm{SiGe}$ layers after laser annealing at laser energy densities of $0.25 \mathrm{~J} / \mathrm{cm}^{2}$ (empty squares), $0.70 \mathrm{~J} / \mathrm{cm}^{2}$ (empty circles) and $1.18 \mathrm{~J} / \mathrm{cm}^{2}$ (stars). In the inset, the complete Raman spectra for laser energy densities of 0.25 and $0.70 \mathrm{~J} / \mathrm{cm}^{2}$ are shown. The region of interest is presented in the left main plot for a better visibility of the $\mathrm{Si}-\mathrm{Si}$ modes contribution from the $\mathrm{SiGe}$ layers and their corresponding Lorentz fits. The right plot shows exemplary the double Lorentz deconvolution. The deconvoluted thin full/thick dashed lines correspond to $\mathrm{Si}-\mathrm{Si}$ modes from $\mathrm{SiGe}$ and $\mathrm{Si}$, respectively. The SiGe Raman peaks shift indicates changes in strain or alloy composition of the layer. ${ }^{18}$ 
by RBS measurements. For a pseudomorphically grown fully strained $\mathrm{Si}_{0.64} \mathrm{Ge}_{0.36}$ film, $\omega_{\mathrm{SiGe}}$ appears at about $509 \mathrm{~cm}^{-1}$, proving that the $\mathrm{SiGe}$ layer is biaxially compressively strained with an in-plane strain value of $1.4 \%$. In fact, the $\mathrm{Si}-\mathrm{Si}$ peak positions of the SiGe layers stay around $509 \mathrm{~cm}^{-1}$ up to a laser energy density of $0.5 \mathrm{~J} / \mathrm{cm}^{2}$, indicating full strain conservation, in agreement with the absence of dislocations (Fig. 4(a)). The peak shift and broadening observed above $0.5 \mathrm{~J} / \mathrm{cm}^{2}$, up to about $0.7 \mathrm{~J} / \mathrm{cm}^{2}$ (Fig. 7(a)), where the $\mathrm{SiGe} / \mathrm{Si}$ substrate interface melts, is attributed to the inhomogeneous depth distribution of the Ge atoms, already observed by SIMS and TEM (Figs. 3(a) and 4(b)). At higher laser energy density, the Si-Si vibration position is shifted to higher wavenumbers. This is in agreement with a reduction of the Ge content in thicker and diluted SiGe layers, as observed by RBS (Fig. 5). Moreover, the shifts correspond to pseudomorphic epitaxial SiGe layers under compressive strain according to the $\mathrm{Ge}$ content. The result of $1.18 \mathrm{~J} / \mathrm{cm}^{2}$ annealing is presented in Fig. 7(b), where the Raman shift indicates an elastic strain of $0.2 \%$ in the newly formed $90 \mathrm{~nm} \mathrm{SiGe} \mathrm{with} \mathrm{a} \mathrm{Ge-}$ content of $8 \%$, as determined by RBS.

\section{Laser annealing modelling}

To further analyze these results and to assess the physical processes for different energy density regimes, a numerical simulation of the temperature profiles in the irradiated volumes has been performed. The numerical approach employed here, predicts the thermal profiles in the structure by solving $f$ the Heat Conduction Differential Equation or each component layer,

$$
\partial H(T) / \partial t=\nabla[k(T) \nabla T(\mathrm{r}, \mathrm{t})],
$$

where $H\left(\mathrm{~J} / \mathrm{cm}^{3}\right)$ denotes the system enthalpy, $T(\mathrm{~K})$ the temperature field, $k\left(\mathrm{~W} / \mathrm{cm}^{2} \mathrm{~K}\right)$ the thermal conductivity and $r, t$ are the position and the time, respectively.

The following boundaries conditions were considered:

$$
-\left.k_{i}(T) \frac{\partial T}{\partial y}\right|_{0}=I_{0}(\vec{r}, t)
$$

on the a-SiGe surface under laser radiation, for $\mathrm{t}>0$,

$$
\begin{aligned}
-\left.k_{j}(T) \frac{\partial T}{\partial y_{j}}\right|_{s_{j-n}}=-\left.k_{n}(T) \frac{\partial T}{\partial y_{n}}\right|_{s_{j-n}} \\
\text { on the } s_{j-n} \text { interfaces a-SiGe, c-SiGe and c-Si, for } \mathrm{t}>0,
\end{aligned}
$$

and the initial condition : $T(\vec{r}, 0)=T_{0}$, in the whole

$$
\text { volume at } \mathrm{t}=0 \text {, }
$$

$k_{i, j, n}$ are the thermal conductivities on the $i, j, n$ position, $I_{o}$ $\left(\mathrm{W} / \mathrm{cm}^{2}\right)$ is the energy density, $T_{m}$ the melting temperature for each layer and $T_{o}$ the ambient temperature of $298 \mathrm{~K}$. The variable $y$ stands for the spatial coordinate normal to the $\mathrm{SiGe}$, surface. For the other interfaces, heat flux fulfills continuity, while the bottom follows an adiabatic behavior for each material. The phase changes are considered by the enthalpy $H,{ }^{19}$

$$
H(T)=\int_{T_{o}}^{\min \left(T ; T_{m}\right)} \rho\left(T^{\prime}\right) C\left(T^{\prime}\right) d T+h\left(T-T_{m}\right) \mathrm{L}_{\mathrm{m}},
$$

where $h$ is the Heaviside function and $L_{m}(\mathrm{~J} / \mathrm{g})$ the melting latent heat. The model considers the temperature dependence of density $\rho\left(\mathrm{g} / \mathrm{cm}^{3}\right)$, thermal conductivity $k\left(\mathrm{~W} / \mathrm{cm}^{2} \mathrm{~K}\right)$, and specific heat $C(\mathrm{~J} / \mathrm{gK}){ }^{20}$

The implementation of the temporal and spatial distribution of the laser pulses, $I_{0}\left(\mathrm{~W} / \mathrm{cm}^{2}\right)$, provided by the Excimer laser, is successfully fitted by the following mathematical expression: ${ }^{19}$

$$
I_{0}(r, t)=\Phi[F, f(\tau)][1-R(n, \kappa)] \exp [-\alpha y],
$$

that considers the main laser parameters: the laser beam energy density $F\left(\mathrm{~J} / \mathrm{cm}^{2}\right)$ and the temporal profile of the pulse $f(\tau)$, the reflectivity $R(n, \kappa)$ with refraction index $n$ and extinction $\kappa$, and absorption coefficient $\alpha\left(\mathrm{cm}^{-1}\right)$ of the surface. $^{21,22}$ For the first $7 \mathrm{~nm}$ thin amorphous SiGe layer, an optical penetration depth of $\alpha^{-1} \sim 6.5 \mathrm{~nm}$ was estimated, ${ }^{23}$ thus the optical effect to the thermal process by means of the Beer-Lambert law additionally been considered. ${ }^{24}$

The numerical model estimates the temperature profiles caused by the first laser pulse. Dopant diffusion below the melting points is not considered in this model. Moreover, the model is limited by the accuracy of the material parameters available and by the approximations for the input data. For example, we have considered the same melting temperature for the strained SiGe layer as for unstrained SiGe, while it has been reported that strain, in particular high compressive strain, induces a decrease of the material melting temperature. ${ }^{25}$ Moreover, additional experimental uncertainties are caused by the $10 \%$ variation of the laser energy at same operating conditions and, especially for the focused beam, by $5 \%-10 \%$ uncertainty in the determination of the spot size.

Nevertheless, these approximations allow simulating temperature profiles that fit reasonably well with the experimental findings. Figs. 8(a)-8(c) show the sample temperature distribution vs. time at different laser energy densities of $0.3 \mathrm{~J} / \mathrm{cm}^{2}, 0.8 \mathrm{~J} / \mathrm{cm}^{2}$, and $1 \mathrm{~J} / \mathrm{cm}^{2}$, respectively. The melting temperature thresholds for the different materials a-SiGe, c-SiGe, and c-Si are marked with horizontal dashed lines. As it can be observed, the amorphized top layer of the "asimplanted" sample starts melting using an energy density around $0.3 \mathrm{~J} / \mathrm{cm}^{2}$, while the underlying $\mathrm{c}-\mathrm{SiGe}$ and $\mathrm{c}-\mathrm{Si}$ reaches only a maximum temperature of around $1100 \mathrm{~K}$ (Fig. 8(a)). For reaching the melting threshold of the buried crystalline $\mathrm{SiGe}$ film, an energy density of $0.8 \mathrm{~J} / \mathrm{cm}^{2}$ is needed (Fig. 8(b)) and at $1 \mathrm{~J} / \mathrm{cm}^{2}$ the complete SiGe layer structure, as well as a fraction of the Si substrate has been molten (Fig. 8(c)). The heating/cooling cycles are clearly on the ns timescale and the molten pool is recrystallizing within few tenths of ns, thus long before the next laser pulse. Small inflection can be observed when the temperatures reach the melting thresholds of the amorphous and crystalline SiGe 

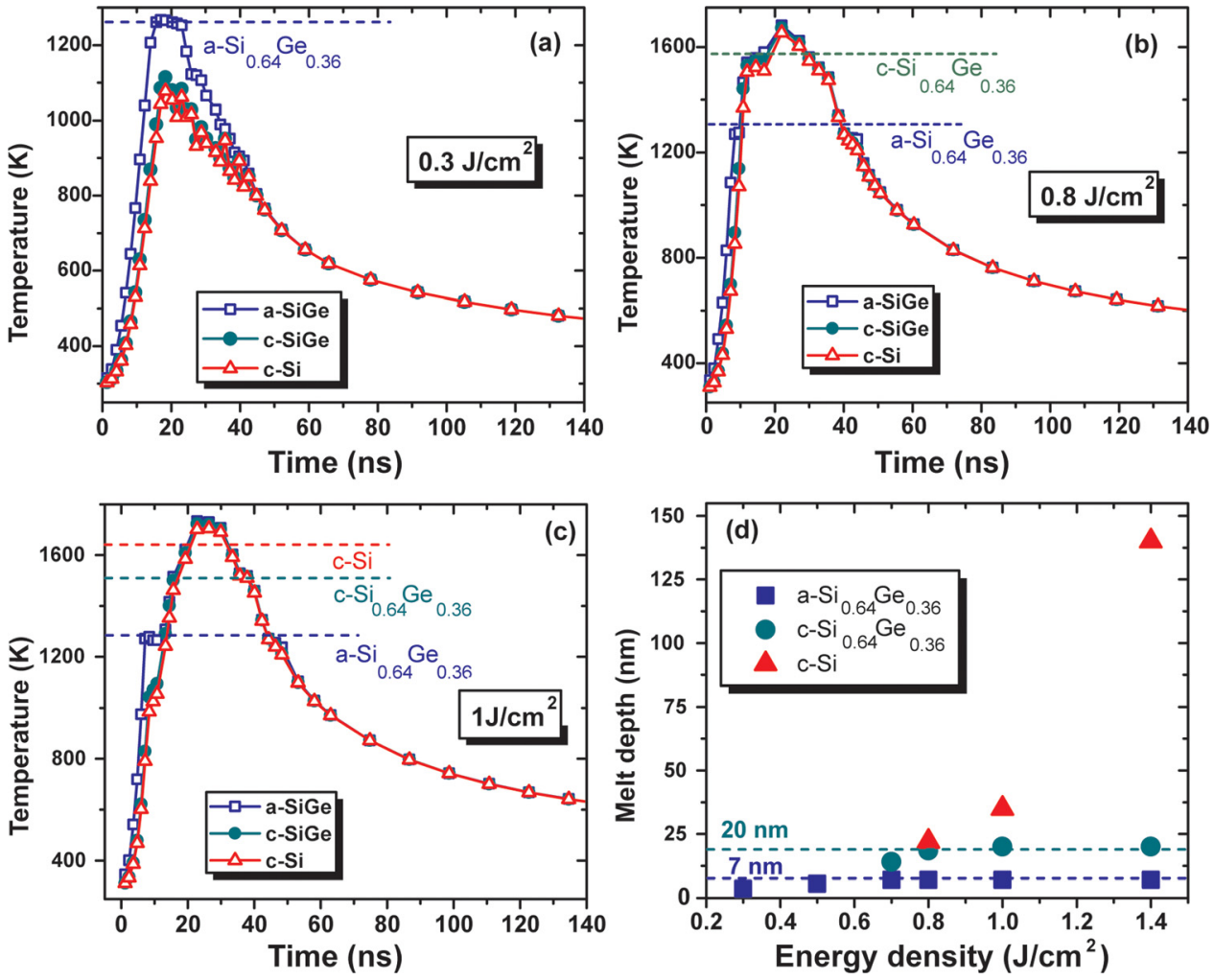

FIG. 8. Modeling results of the sample temperature distribution at laser energy densities of (a) $0.3 \mathrm{~J} / \mathrm{cm}^{2}$, (b) $0.8 \mathrm{~J} / \mathrm{cm}^{2}$ and (c) $1 \mathrm{~J} / \mathrm{cm}^{2}$. A $7 \mathrm{~nm}$ a-SiGe/13 nm $\mathrm{c}-\mathrm{SiGe} / \mathrm{c}-\mathrm{Si}$ structure was considered and the melting temperature at different interfaces is marked. (d) Maximum melting depth for every layer function of energy density. layers, which are attributed to the phase changes, thus variation of temperature dependent thermal properties that are considered by the enthalpy in Eq. (4).

Figure 8(d) summarize the maximum melting depth vs. the energy density, indicating the position of the different interfaces between layers by horizontal lines. As it can be observed, using energy densities higher than $0.3 \mathrm{~J} / \mathrm{cm}^{2}$ always melt the amorphous layer, while at least around $0.6-0.7 \mathrm{~J} / \mathrm{cm}^{2}$ and $0.8 \mathrm{~J} / \mathrm{cm}$ are needed to melt also the $\mathrm{c}-\mathrm{SiGe}$ and a fraction of the $\mathrm{c}-\mathrm{Si}$, respectively.

\section{DISCUSSION}

The above results indicate that for understanding the electrical results presented in Figs. 1 and 2 both, the redistribution of As and B in/from the SiGe layer and the Si substrate, as well as the evolution of the SiGe layer composition and thickness have to be taken into account.

After laser annealing, we observed a redistribution of the As that resembles the as-implanted profile in the area recrystallized from solid state (up to $0.3 \mathrm{~J} / \mathrm{cm}^{2}$ ) but increases in the molten and solidified regions (Figs. 3(b) and 5(b)). At low energy densities annealing, most of the dopant atoms reside in a thin near-surface layer (Fig. 3), whereas annealing with a higher energy density results in dopant diffusion from this layer far toward the bulk crystal (Fig. 5(b)).

For dopant activation, two conditions must be fulfilled: (i) The supply of vacancies/removal of self-interstitial atoms, during the available time, must be sufficient to provide the required substitutional sites for a substantial fraction of the implanted As atoms, and (ii) the resulting high temperature solution of As atoms must be frozen-in sufficiently rapidly to avoid significant As precipitation. ${ }^{9}$
In the low energy density range below $0.3 \mathrm{~J} / \mathrm{cm}^{2}$, according to our simulation, we may consider that the complete laser energy delivered to the system is absorbed in the highly damaged ion implanted layer. The system heats up and evolves similar to a high temperature rapid thermal annealing (RTA) process: The As incorporation in the crystal lattice positions is, therefore, assumed to take place by Solid-Phase Epitaxial Regrowth (SPER) of the a-SiGe. At $0.3 \mathrm{~J} / \mathrm{cm}^{2}$, melting of the $\sim 7 \mathrm{~nm}$ thin a-SiGe layer occurs, as indicated by the ELA modelling (Fig. 8(a)) and leads to a removal of the implantation induced damage and the epitaxial recrystallization of the molten layer on the single-crystal substrate. ${ }^{26}$ The As incorporation is accomplished during re-crystallization from the liquid phase (LPER) taking the underlying SiGe lattice as seed. At this energy density, the As activation amounts to $1.5 \%$ of the total implanted dose (Fig. 2). Activation now increases drastically with the depth of the molten region until the complete SiGe layer has melted (Fig. 9). Differently from RTA where the diffusion, characterized by solid state diffusion coefficients, is insignificant due to short annealing time (nsrange), in the liquid phase the diffusion can be $10^{5}$ times larger than in solid phase. ${ }^{27,28}$ As a result, the As atoms redistribute through the molten region, as confirmed by our SIMS data (Fig. 3). Up to a laser energy density of $0.7 \mathrm{~J} / \mathrm{cm}^{2}$ when also Si starts melting, a "hot SiGe fluid" is confined up to the interface with the $\mathrm{Si}$ substrate and the fast motion of the atoms in fluid results in a non-uniform Ge depth distribution (Figs. 3(a) and 6(b)). While the ns-time scale of the cooling is longer than the times of most major relaxation processes (electron-electron, electron-lattice, etc.), the heat diffusion into the Si substrate (heat sink) cools the material while forming an epitaxial single crystal (Figs. 4(a) and 4(b)), adapting the state of lowest energy. ${ }^{29}$ 


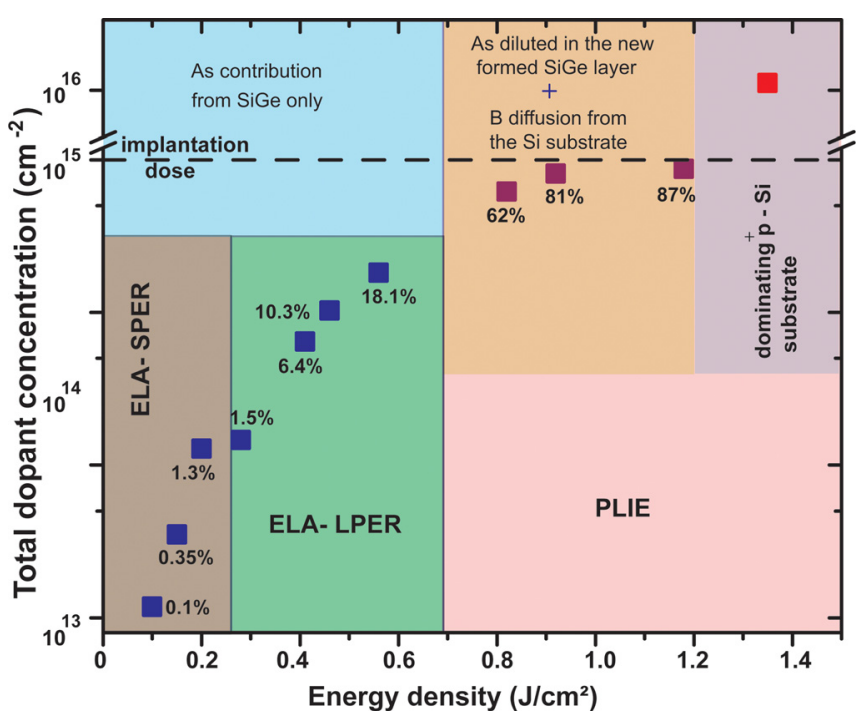

FIG. 9. Total dopant $(\mathrm{As}+\mathrm{B})$ concentration and dopant activation in percent versus laser annealing density. The various scenarios of dopant contribution and $\mathrm{SiGe}$ layer formation processes are indicated.

Above the Si melting threshold at around $0.7 \mathrm{~J} / \mathrm{cm}^{2}$, the laser process resembles pulsed laser induced epitaxy (PLIE). ${ }^{30,31}$ These newly formed SiGe layers grow pseudomorphic on the $\mathrm{Si}$ substrate, similar as for the previous LPER energy density regime. The difference here is the intermixing of the $\mathrm{SiGe}$ layer with the $\mathrm{p}^{+}$-type $\mathrm{Si}$ substrate (Fig. 5(a)). Consequently, both dopant species, As from the initial SiGe layer and B from the Si substrate will be incorporated into the recrystalized SiGe layer (Fig. 4(c)). While the Ge content decreases drastically down to $8 \%$, we can consider the solid solubility for B and As in the new SiGe layer to be similar to that of pure Si. However, the increased activation with laser energy is not surprising for the temperatures/time scales considered in this paper: The effective solubility that matters here is that at the "kinetic freezing point" of the solution, which depends on the maximum temperature reached in the samples and cooling rate (ns in our case). With orders of magnitude higher cooling rates, ELA is clearly superior to RTA in this respect. Van Vechten et al. ${ }^{32,33}$ suggested that an electron-hole plasma forms under high laser energy densities which persists for a very long time and leads to efficient annealing via two mechanisms: (i) the substantial reduction in the number of bonding electrons that "fluidize" the irradiated material which would subsequently undergo a second order transition; and (ii) the presence of the plasma that could permit enhanced vacancy diffusion which allows enhanced activation. However, this plasma annealing theory has been criticized and is not generally accepted. ${ }^{34}$

The activation of both, As and B atoms strongly influences the electrical characterization of the SiGe layers while both, holes and electrons will contribute to the electrical measurements. In order to estimate the influence of the B codoping on the electrical properties of As doped SiGe layers, similar experiments as presented for As have been performed with B doped samples. Table I shows a comparison of the sheet carrier concentration and the activation degree for $\mathrm{B}$ and As dopants achieved at two different laser energy densities (typical SPER and LPER conditions) and three RTA temperatures. Note that for comparing the effects on different dopants, the activation is summarized only in the ELA range where no Si melting occurs (no substrate or electrical isolation layer influence).

For both, RTA and ELA processes, B activation was found to be superior compared to As. Moreover, for the RTA samples, the B activation increases with the temperature, in the regions investigated, while the As seems to saturate at about $15 \%-16 \%$. However, it has to be taken into account that higher temperate annealing, above the layer growth temperature, results in elastic strain relaxation via dislocation formation, with a detrimental effect on devices performance. The laser annealed samples results, therefore, in a better As activation only at laser energy densities that melting the complete SiGe layer.

\section{CONCLUSIONS}

A detailed experimental study on As doping of highly strained SiGe layers by excimer laser annealing (ELA) has been carried out and the results were related to the evolution of thermal profiles, as simulated by FEM. The most important finding is that about $20 \%$ of implanted As can be electrically activated without changing the SiGe concentration profile and strain status using ELA. This is about 10 times more than obtained by standard RTA. Layer melting at intermediate laser power is necessary to achieve small sheet resistances and to activate high As concentrations. The liquid-solid recrystallization results in singe-crystalline $\mathrm{SiGe}$ alloys that are pseudomorphic with respect to the Si substrate, thus strain properties of the initial layer structure can be maintained. Modelling of the melting and epitaxial

TABLE I. Sheet concentration and dopant activation degree for B and As dopants using different annealing conditions.

\begin{tabular}{|c|c|c|c|c|c|}
\hline \multirow[b]{2}{*}{ Process } & \multirow{2}{*}{$\begin{array}{c}\text { Temperature/energy } \\
\text { density }\end{array}$} & \multicolumn{2}{|c|}{ Boron } & \multicolumn{2}{|c|}{ Arsenic } \\
\hline & & Sheet conc. $\left(\mathrm{cm}^{-2}\right)$ & Activation degree & Sheet conc. $\left(\mathrm{cm}^{-2}\right)$ & Activation degree \\
\hline RTA & $600^{\circ} \mathrm{C}$ & $1.5 \times 10^{14}$ & $15 \%$ & $1.3 \times 10^{14}$ & $13 \%$ \\
\hline RTA & $650^{\circ} \mathrm{C}$ & $2 \times 10^{14}$ & $20 \%$ & $1.5 \times 10^{14}$ & $15 \%$ \\
\hline RTA & $700^{\circ} \mathrm{C}$ & $6 \times 10^{14}$ & $60 \%$ & $1.6 \times 10^{14}$ & $16 \%$ \\
\hline ELA & $0.15 \mathrm{~J} / \mathrm{cm}^{2}$ & - & - & $3.5 \times 10^{12}$ & $0.35 \%$ \\
\hline ELA & $0.28 \mathrm{~J} / \mathrm{cm}^{2}$ & $4 \times 10^{13}$ & $4 \%$ & $1.5 \times 10^{13}$ & $1.5 \%$ \\
\hline ELA & $0.51 \mathrm{~J} / \mathrm{cm}^{2}$ & $9.9 \times 10^{14}$ & $99 \%$ & $1.8 \times 10^{14}$ & $18 \%$ \\
\hline
\end{tabular}


recrystallization by laser annealing can assess the depth of the activation region, preventing intermixing and dopant redistribution.

\section{ACKNOWLEDGMENTS}

The authors would like to thank J. Szillinski and C. Scholtysik for performing the ion implantations, S. Lenk for the electron microscopy and M. Hülsbeck for the Raman spectroscopy measurements. Numerical simulation has been partially financed by Spanish (MAT2011-24077) and Galician (2010/83) grants, co-financed by FEDER funds.

${ }^{1}$ S. Wirths, A. T. Tiedemann, Z. Ikonic, P. Harrison, B. Holländer, T. Stoica, G. Mussler, M. Myronov, J. M. Hartmann, D. Grützmacher, D. Buca, and S. Mantl, Appl. Phys. Lett. 102, 192103 (2013).

${ }^{2}$ R. Minamisawa, S. Habicht, D. Buca, R. Carius, S. Trellenkamp, K. K. Bourdelle, and S. Mantl, J. Appl. Phys. 108, 124908 (2010).

${ }^{3}$ E. Bruno, G. G. Scapellato, G. Bisognin, E. Carria, L. Romano, A. Carnera, and F. Priolo, J. Appl. Phys. 108, 124902 (2010).

${ }^{4}$ Q. Zhang, J. Huang, N. Wu, G. Chen, M. Hong, L. K. Bera, and C. Zhu, IEEE Electron Device Lett. 27, 728 (2006).

${ }^{5}$ M. Schmidt, R. A. Minamisawa, S. Richter, A. Schäfer, D. Buca, J. M. Hartmann, Q.-T. Zhao, and S. Mantl, Appl. Phys. Lett. 101, 123501 (2012).

${ }^{6}$ R. Minamisawa, M. Schmidt, L. Knoll, D. Buca, Q. T. Zhao, J. M. Hartmann, K. K. Bourdelle, and S. Mantl, IEEE Electron Device Lett. 33, 1105 (2012).

${ }^{7}$ W. Yu, B. Zhang, Q. T. Zhao, D. Buca, J. Hartmann, R. Lupták, G. Mussler, A. Fox, K. K. Bourdelle, X. Wang, S. Mantl, and A. Hole, IEEE Electron Device Lett. 33, 758 (2012).

${ }^{8}$ R. Minamisava, D. Buca, W. Heiermann, F. Lanzerath, S. Mantl, W. Skorupa, J.-M. Hartmann, B. Ghyselen, N. Kernevez, and U. Breuer, ECS Trans. 19, 79 (2009).

${ }^{9}$ F. Lanzerath, D. Buca, H. Trinkaus, M. Goryll, S. Mantl, J. Knoch, U. Breuer, W. Skorupa, and B. Ghyselen, J. Appl. Phys. 104, 044908 (2008).

${ }^{10}$ G. H. Wang, E.-H. Toh, X. Wang, S. Tripathy, T. Osipowicz, T. K. Chan, K.-M. Hoe, S. Balakumar, G.-Q. Lo, G. Samudra, and Y.-C. Yeo, Appl. Phys. Lett. 91, 202105 (2007).
${ }^{11}$ J. T. Smith, C. Sandow, S. Das, R. A. Minamisawa, S. Mantl, and J. Appenzeller, IEEE Trans. Elec. Dev. 58, 1822 (2011).

${ }^{12} \mathrm{~S}$. Wirths, D. Buca, A. T. Tiedemann, P. Bernardy, B. Holländer, T. Stoica, G. Mussler, U. Breuer, and S. Mantl, Solid-State Electron. 83, 2 (2013).

${ }^{13}$ J. F. Ziegler, J. P. Biersack, and U. Littmark, The Stopping Range of Ions in Solids (Pergamon, New York, 1985).

${ }^{14}$ R. Minamisawa, D. Buca, B. Holländer, J. M. Hartmann, K. K. Bourdelle, and S. Mantl, J. Electrochem. Soc. 159, H44 (2012).

${ }^{15}$ D. K. Schroder, Semiconductor Material and Device Characterization (Wiley, New York, 1990).

${ }^{16}$ L. Vincent, F. Fossard, T. Kociniewski, L. Largeau, N. Cherkashin, M. J. Hytch, D. Debarrea, T. Sauvage, A. Claverie, J. Boulmer, and D. Bouchier, Appl. Surf. Sci. 258, 9208 (2012).

${ }^{17}$ N. Semmar, M. Darif, E. Millon, A. Petit, H. Etienne, and P. Delaporte, AIP Conf. Proc. 1464, 298 (2012).

${ }^{18}$ H. Chen, Y. Li, C. Peng, H. Liu, Y. Liu, Q. Huang, J. Zhou, and Q.-K. Xue, Phys. Rev. B 65, 233303 (2002).

${ }^{19}$ J. C. Conde, E. Martín, S. Chiussi, F. Gontad, C. Serra, and P. González, Appl. Phys. Lett. 97, 014102 (2010).

${ }^{20} \mathrm{M}$. W. Chase, NIST-JANAF Thermochemical Tables, 4th ed. (The American Chemical Society and the American Institute of Physics, USA, 1998).

${ }^{21}$ E. D. Palik, Handbook of Optical Constant of Solids (Academic Press, USA, 1985).

${ }^{22}$ L. Ward, The Optical Constants of Bulk Materials and Films (IOP Publishing Ltd, Bristol and Philadelphia, 1994), p. 293.

${ }^{23}$ W. Szyszko, Appl. Surf. Sci. 90, 325 (1995).

${ }^{24}$ M. von Allmen, J. Appl. Phys. 47, 5460 (1976).

${ }^{25}$ A. Natori, H. Harada, N. Wu, and H. Yasunaga, Appl. Surf. Sci. 169-170, 20-24 (2001).

${ }^{26}$ D. Klinger, J. Auleytner, A. Barcz, and D. Żymierska, J. Alloys Compd. 362, 265 (2004)

${ }^{27}$ A. G. Cullis, Rep. Prog. Phys. 48, 1155 (1985).

${ }^{28}$ R. F. Wood, J. R. Kirkpatrick, and G. E. Giles, Phys. Rev. B 23, 5555 (1981).

${ }^{29}$ E. J. Yoffa, Appl. Phys. Lett. 36, 37 (1980).

${ }^{30}$ S. Stefanov, J. C. Conde, A. Benedetti, C. Serra, and J. Werner, Appl. Phys. Lett. 100, 204102 (2012).

${ }^{31}$ S. Stefanov, J. C. Conde, A. Benedetti, C. Serra, J. Werner, M. Oehme, and J. Schulze, Appl. Phys. Lett. 100, 104101 (2012).

${ }^{32}$ J. A. Van Vechten, R. Tsu, and F. W. Saris, Phys. Lett. A 74, 422 (1979).

${ }^{33}$ J. A. Van Vechten, R. Tsu, F. W. Saris, and D. Hoonhout, Phys. Lett. A 74, 417 (1979).

${ }^{34}$ G. Wartmann, M. Kemmler, and D. von der Linde, Phys. Rev. B 30, 4850 (1984). 